\title{
Rook Spring Seed Dispersal in the Agricultural Landscape - Frugivory, Granivory or Accidental Transport?
}

\author{
Joanna Czarnecka • Ignacy Kitowski
}

(C) The Author(s) 2012. This article is published with open access at Springerlink.com

\begin{abstract}
Seed dispersal seems to be extremely important in agrocoenoses where suitable habitats (patches) are surrounded by an unfavourable environment (matrix). The role of the rook Corvus frugilegus, an omnivorous bird, in seed dispersal was studied in the agricultural landscape of Eastern Poland. We analyzed 739 pellets produced by regurgitation, which were collected under breeding colonies in April, May and June. Our goal was to $i$ ) assess the structure of the seed pool in pellets; ii) evaluate the temporal variation in the pellet seed pool on two different time scales; iii) compare the species composition of seeds in pellets and vegetation under the rook nests. Seeds were present in $18 \%$ of pellets; 571 seeds were found, half of them belonging to dry-fruited species, without any obvious adaptations to endozoochory. These seeds could be an additional source of food, or they could have been accidentally swallowed during foraging for other food items. Taking into consideration the abundance of the rook population, we assessed the mean number of seeds transferred by one bird to be from 4 seeds per month in April and up to 160 seeds in June. The most important factor responsible for qualitative and quantitative structure of seed pool in pellets is the time when pellets were regurgitated. The type and availability of food determines the number and species structure of dispersed seeds. The comparison of the species structure of the seed pool in pellets and of the herb layer under the breeding colonies showed that the rook could effectively disperse seeds of weeds, meadow and ruderal species, that could germinate under the dense canopy of trees at the studied sites.
\end{abstract}

Electronic supplementary material The online version of this article (doi:10.1007/s12224-012-9134-0) contains supplementary material, which is available to authorized users.

J. Czarnecka $(\bowtie)$

Ecology Department, Institute of Biology and Biochemistry,

Maria Curie-Skłodowska University, Akademicka 19,

20-033 Lublin, Poland

e-mail: a_czarnecki@wp.pl

I. Kitowski

State School of Higher Education in Chełm, Pocztowa 54, 20-100 Chełm, Poland

e-mail: ignacyk@autograf.pl 
Keywords Endozoochory $\cdot$ Regurgitation pellets $\cdot$ Secondary dispersal $\cdot$ Seed predation . Weeds

Plant nomenclature Mirek et al. (2002)

\section{Introduction}

Species composition is a function of the availability of seeds and safe sites suitable for germination. Dispersal limitation is often crucial for local species composition and vegetation structure (Eriksson and Ehrlén 1992; Wang and Smith 2002; Ozinga et al. 2005). Plant movement is limited to the dispersal of seeds and pollen and it is usually mediated by animal agents, wind, water, gravity or caused by intrinsic explosive mechanisms (Wang and Smith 2002; Jordano et al. 2011). Many plants in most plant communities rely on animal-mediated mechanisms, with endozoochory being one of the most effective dispersal modes. Animals consuming fruits and seeds (frugivores and granivores) influence regeneration cycles of more than half of the plant species (Howe and Smallwood 1982; Wang and Smith 2002). Frugivory has been examined as a mutualistic interaction between animals and plants, while granivory has been viewed as an antagonistic interaction within the broader field of herbivory, but many vertebrates subsist on a diet of both fruits and seeds (Levey et al. 2002). Large herbivores can also contribute to the dispersal of some seeds while eating the foliage of parent plants (Janzen 1984). All these plant-animal interactions have been occurring for millions of years and some special traits of seeds and fruits were selected to attract animals, enhance survival in gut and increase edibility of the plant vegetation at the time of seed and fruit ripening (Janzen 1984; Pakeman et al. 2002).

Animals are often involved in complex dispersal systems (Nogales et al. 1998, 2007). They can be a vector in multi-step dispersal processes called diplochory or polichory, when seeds are dispersed in two or more phases. Combination of a few different mechanisms often provides greater benefits than do most single means. These benefits are mostly the extension of dispersal distance and moving seeds to safe germination sites (Vander Wall and Longland 2004). Animals can also play a role in secondary dispersal, when seeds that are on the ground are moved to other locations, and as a vector in non-standard dispersal, when a factor which cannot be linked to seed morphology is involved in seed spreading (Wang and Smith 2002; Higgins et al. 2003).

The role of birds in plant dispersal cannot be overestimated. Bird vectors may be the prime means of achieving larger seed dispersal distances and they play the dominant role in rapid migrations of plant species, even those without any adaptations to endozoochory (Wilkinson 1997). The awareness of the diverse ecological functions of birds increased significantly during the last few years - seed dispersal is one of the most important and least appreciated forms of birds' contribution, enabling the colonization of marginal and isolated habitats (Sekercioglu 2006; Spiegel and Nathan 2007; Garcia et al. 2010). In the traditional man-shaped landscape most habitats are connected by dispersal processes (Poschold and Bonn 1998) and the probability of recolonization depends on the spatial relationship among landscape elements 
(patches, matrix and corridors), dispersal ability of organisms and temporal changes in landscape structure (Fahring and Merriam 1992). The increasing isolation of suitable habitats, called patches, leads to the growing importance of long-distance dispersal, and the latter becomes crucial for the persistence of species in a fragmented agricultural landscape (Ozinga et al. 2004; Trakhtenbrot et al. 2005), especially in the case of weed seeds, most of which have developed no dispersal mechanisms and their dispersal is limited (Benvenuti 2007).

Corvids are a group of birds strongly connected with man-shaped landscapes in Central Europe, and all of them are omnivorous species (Tryjanowski et al. 2009). Until now the role of this widely distributed and abundant group of birds in seed spreading has been poorly studied, although their diet and feeding behaviour has been examined carefully (e.g., Gromadzka 1980; Kasprzykowski 2003; Orłowski et al. 2009). They feed on a great variety of plant and animal material and usually rely on the easiest accessible food at the particular moment (Tryjanowski et al. 2009). Their feeding behaviour provides many species of different dispersal adaptations with a great opportunity of spreading. Frugivory mediated by corvids (the common raven Corvus corax, the magpie Pica pica and the carrion crow Corvus corone) was most frequently reported in the literature (Reebs and Boag 1987; Nogales et al. 1999; Jordano et al. 2007). The particular importance of this group of birds (the magpie, the rook and the jackdaw Corvus monedula) was also noticed because of their habit of cacheing food (Wilkinson 1997; Lenda and Skórka 2009; Lenda et al. 2012). Information on the internal transport of seeds of dry-fruited species, as a consequence of corvids' granivory, is scattered and lacks quantitative character, e.g., the presence of weed seeds in stomach content was mentioned in a work concerning the rook diet (Gromadzka 1980).

We decided to check the potential role of the rook Corvus frugilegus L. in the process of seed dispersal in an agricultural landscape. Its diet has been studied carefully because of the bird's reputation as a harmful grain-eater gained in the past. The main component of its plant diet is cereal grain. Fruits also constitute an important part of the diet, when this kind of food is available (Jabłoński 1979; Gromadzka 1980). The feeding behaviour of the species suggests that it can be an effective dispersal vector for many fleshy-fruited and dry-fruited plants on the landscape and regional scale. The rook-mediated dispersal events can mainly lead to the increase of biodiversity of patches in the agricultural landscape, where seeds from the other landscape elements (matrix, corridors and also the other patches) are placed.

The present study aims to evaluate the potential role of the rook in spring seed dispersal (April-July), by assessing the seed pool in regurgitation pellets. Spring was chosen because the ratio of bird (and hence pellet) concentration in one location (the rooks' breeding colonies) to quantity of transported seeds is at its highest, as compared to winter (high pellet/low seed concentration) and summer/fall (low pellet because of scattered deposition/high seed concentration). The lowest number of transported seeds in spring was also observed during the studies of endozoochorous dispersal by large herbivores (Myers et al. 2004). We wanted to $i$ ) assess the structure of the seed pool in pellets; $i$ ) evaluate the temporal variation in the regurgitation pellet seed pool in two different time scales; iii) compare the species composition of seeds in pellets and vegetation under the rook nests to assess if germination and 
establishment is possible under breeding colonies of the rook. We expected that two factors could be potentially responsible for the structure of the seed pool of pellets: the time of pellet formation and the structure of agricultural landscape that serves as a feeding place for the birds. We tested the germination ability of retrieved seeds and we assessed the possibility of post-dispersal establishment of seeds in habitats where pellets were located. We also discussed the effectiveness (sensu Shupp 1993) of seed dispersal, the importance of the rook in secondary dispersal, and the role of this bird in non-standard seed dispersal processes.

\section{Material and Methods}

\section{Study Object}

The rook (Corvus frugilegus) is a forest-steppe species, currently one of the most numerous species in agroecosystems, but its population in Poland is difficult to estimate. Studies on a regional scale suggest that ca. 285,500 pairs (about 100 pairs $/ 100 \mathrm{~km}^{2}$ ) presently live in Poland, and this number was even higher, reaching 400,000 pairs in the 1980s (Jakubiec 2005a; Tryjanowski et al. 2009). The rooks' feeding range varies throughout the year. They feed from $0.5-2 \mathrm{~km}$ from the breeding colony (Patterson et al. 1971; Kasprzykowski 2003); in the case of wintering birds the distance can be higher as they forage even $10-40 \mathrm{~km}$ away from the winter roosts (Jadczyk and Jakubiec 2005). The mosaic of small fields is preferred by foraging birds, with meadows and pastures constituting the crucial type of foraging area for rooks. Spring cereals, winter crops, root plants, ploughed fields, maize and wastelands are also visited (Jakubiec 2005b). Preliminary studies of the content of the pellets produced by regurgitation showed that rooks can transport many seeds from foraging areas into breeding colonies and winter roosts (Czarnecka and Kitowski 2010), which are located almost exclusively in the close vicinity of man's settlements, in various groups of trees, old parks and burial grounds (Jadczyk and Jakubiec 2005; Ptaszyk and Winiecki 2005). The rook's diet contains plant (mainly the grain of cereals and smaller numbers of seeds of other plants) and animal items in nearly equal proportions throughout the year (Jabłoński 1979; Gromadzka 1980). One bird's mean number of pellets ranges from 0.7 to 1.1 per day, and the maximum number observed in aviary conditions is 3 (Luniak 1977).

\section{Study Area and Methods}

Regurgitation pellets were collected from seven breeding colonies (rookeries); six were located in rural parks in villages near three cities of eastern Poland: Lublin, Zamość and Chełm; one breeding colony was situated in the park on the outskirts of Chełm. The size of studied colonies ranged between 55 and 583 pairs (Table 1, codes A $-\mathrm{G}$ for colonies are further used). The survey of the number of nests and birds was carried out between the 15th and 30th April 2009. This kind of observation always takes place before the appearance of foliage on trees, facilitating the counting of birds and bird nests (Biaduń 2005; Orłowski and Czapulak 2007; Państwowy Monitoring Środowiska 2007). For each colony we could distinguish three sub-colonies - distinct 


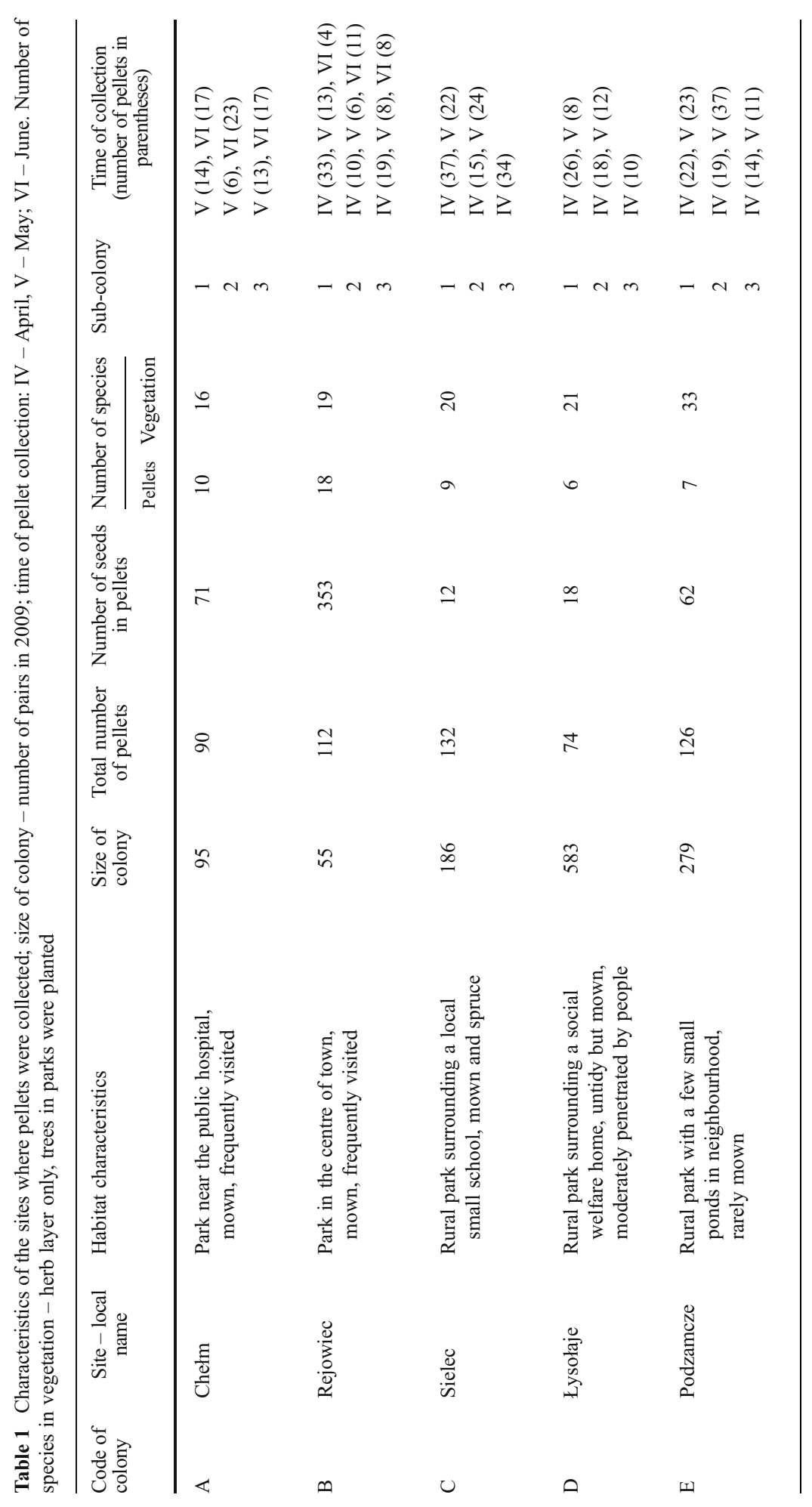




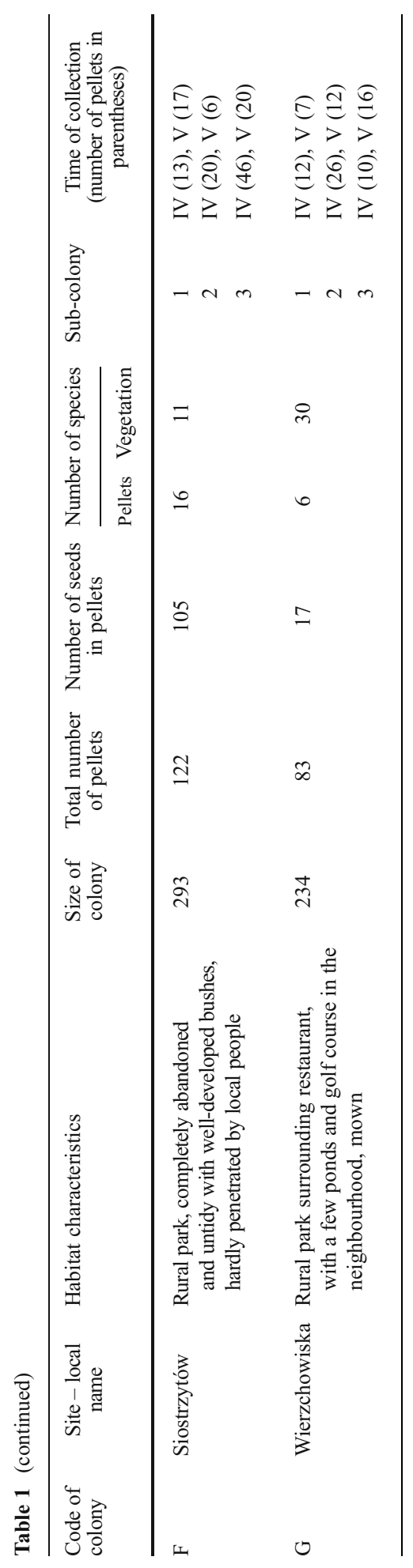


groups of nests isolated from the others (e.g., a group of nests located on one tree). We visited each colony three times, at the end of April (IV), May (V) and June (VI) 2009, and collected all available pellets. Each time the whole ground just under the particular group of nests (called sub-colony, indicated with numbers 1-3 after the colony code) was examined carefully and all the pellets present there were collected. The examined area was approximately a few dozens of square meters in the case of each sub-colony. Only in the case of one colony (B code) could we collect three sets of pellets; in the remaining cases only twice. Pellets collected under each sub-colony were treated separately.

Pellets were dried, weighed and examined under the magnification 10×; all seeds and other items (fragments of cereal grains, stones, fragments of paper, plastic bags, aluminium foil, glass etc.) were separated and identified. When all the pellets were examined, all the separated seeds were sown into garden soil and put into the greenhouse in March 2010 to check their germination ability. Seeds separated earlier were stored dry in room temperature until sowing time, similarly to the pellets awaiting analysis. Storage conditions were the same for seeds present in pellets and those already extracted. We decided to sow all separated seeds at the same time to reduce the differences in germination ability caused by the differences in time and storage conditions. This enabled us to compare the germination test results among the different species and seeds separated from pellets at different times. The observation of germination was terminated after 100 days. To check the possibility of germination of species present in pellets all colonies were visited in July 2009. Vegetation under the colony was examined carefully, all species represented by established individuals were noted and their abundance was evaluated.

Because of the high proportion of pellets without any seeds (high proportion of zero values obtained) we could apply non-parametric tests $\left(\chi^{2}\right.$ likelihood ratio, Kruskal-Wallis test, U Mann-Whitney test) and the Spearman rank correlation coefficient $\left(r_{\mathrm{s}}\right)$. In some cases data were expressed as mean values per 100 pellets to enable comparisons between different data sets. The Detrended Components Analysis (DCA) was conducted to estimate the level of similarity among pellets of different sub-colonies collected in three subsequent months (Table 1, N=43); it also helped to identify main factors responsible for the differences in the structure of seed pools of pellets. Two main assumptions had been made before the analysis was run: $i$ ) if time is the most important factor responsible for differences in pellet structure, then pellets collected in different months should form three distinct groups; $i$ ) because we did not conduct a detailed survey of foraging preferences of birds from the studied colonies we assumed that birds nesting in one colony would forage at the same habitat types, where food is easily attainable. It is known that the food source within a 1-km radius of the rookery is the most important for the rook (Kasprzykowski 2003). If the habitat types present around the colony were the most important factor influencing the seed pool and structure of pellets, then pellets collected under the same colony (coming from three sub-colonies for each particular colony) should be much more similar to each other than to the pellets originating from other rookeries. The following features of pellets were taken into consideration when DCA was performed: total number of species, number of fleshy-fruited and dry-fruited species, frequency of fragments of cereal grains (the percentage of pellets that contained fragments of cereal grains), mean number of cereal grains per pellet, all groups of seeds, seeds of fleshy-fruited 
and dry-fruited species. To analyze seed pool data the MVSP (Kovach 2005) and Statistica.Pl software was used. This analysis was the only one in which data from subsequent sub-colonies were treated separately. In the other cases the seed pool of pellets collected at the same time (April, May, June) or under the same colony (codes A-G) was analyzed.

We assumed that seed persistence was a key feature that guaranteed successful post-dispersal establishment in the habitats under rook colonies. The longevity index (LI; in Table S1 in Electronic Supplementary Material) was calculated for all recorded species according to Thompson et al. (1998) on the basis of the data from Thompson et al. (1997). It varies between 0 and 1; higher values indicate that species create persistent seed banks.

To check if the intensity of seed dispersal mediated by the rook varies between years seed pools of pellets collected at the same site in two subsequent years (2008 and 2009) were compared. Published data from 2008, when pellets were collected in June (Czarnecka and Kitowski 2010) was then used. We could compare the structure of seed pools from four sites (A, C, D, F); pellets collected at the end of April 2009 were excluded from the analysis to make the data more comparable. Principal Components Analysis (PCA) was used to compare the seed pool in pellets (quantitative data were used). We also compared the share of three main groups of species (fleshyfruited, dry-fruited and cereals) using $\chi^{2}$ likelihood ratio between the data from two subsequent years.

\section{Results}

The content of 739 pellets - 384 collected in April, 275 in May and 80 in June - was analyzed. The main substratum of pellets was plant material with a small admixture of chitin fragments of insects. We also found egg shells, fragments of bones and some "rubbish items" like paper, plastic bags, aluminium foil, bricks, glass and string. In the total number (739) of analyzed pellets 78 cereal grains (mainly wheat) and other 571 seeds were found: 277 (48.5\%) of dry-fruited and 294 (51.5\%) of fleshy-fruited species. The Detrended Correspondence Analysis (DCA) showed that the main factor responsible for the different content was the time when the pellet was regurgitated (Fig. 1). Seasonal changes in the diet of the rook but also the rising availability of fruits and seeds between April and June caused the evident increase of the number of seeds in pellets (Table 2). The rook's basic food in April seemed to be cereal grain. The situation changed in June when the diet became more varied: fragments of cereal grains were present in $95 \%$ of pellets from April and only in $39 \%$ pellets from June. The frequency of pellets with seeds of dry-fruited and fleshy-fruited species increased at the same time (from $4 \%$ up to $17 \%$ for dry-fruited species and from $2 \%$ up to $34 \%$ for fleshy-fruited species from April to June in both cases). The frequency of cereal grain fragments was significantly negatively correlated with both the number of other seeds and the number of species present in pellets $\left(r_{\mathrm{S}}=-0.53, P<0.001\right.$ and $r_{\mathrm{S}}=-0.42, P<0.01$, respectively). Although we observed a huge increase in the number of seeds in June (362 seeds found in 80 analyzed pellets in comparison to 40 seeds in 384 pellets in April, and 169 in 275 pellets in May; mean values in Table 2), we must emphasize that the distribution of seeds in pellets was extremely 


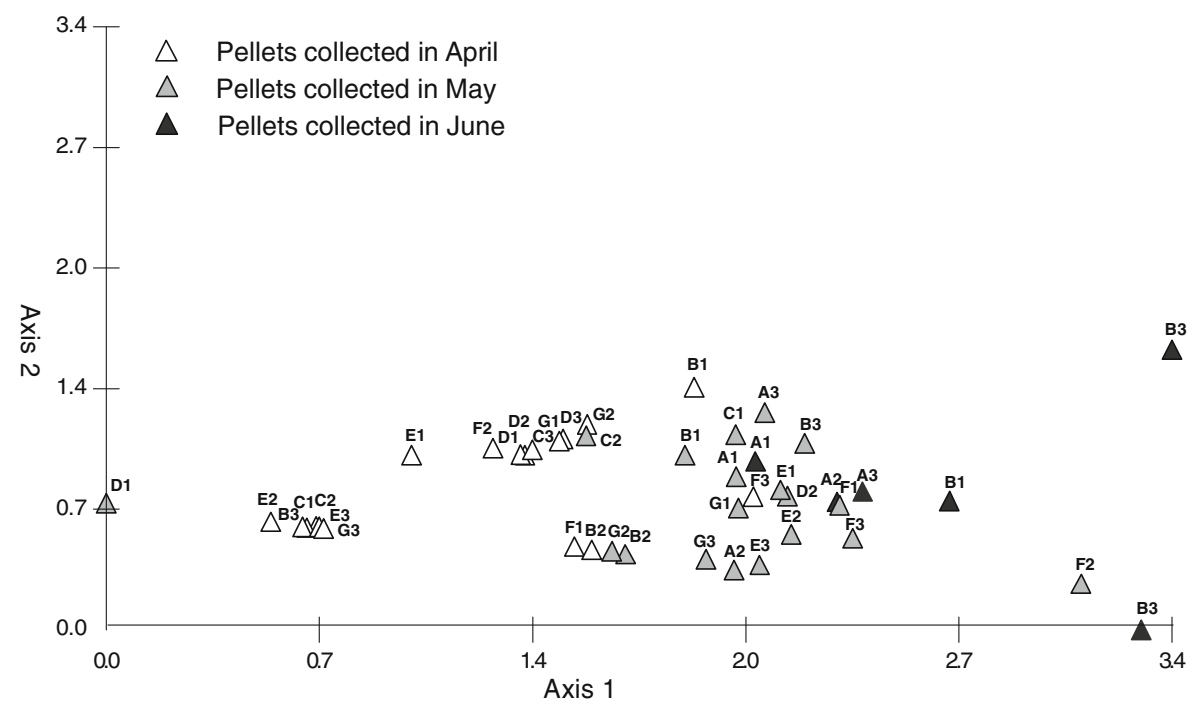

Fig. 1 Results of the DCA of variables characterizing seed pools at different sites. Letters $(A-G)$ indicate colonies and numbers (1-3) sub-colonies. Eigenvalues: Axis $1-0.418$, Axis 2 - 0.170; cumulative percentage: Axis $1-41.334$, Axis $2-58.157$. Statistically significant Spearman rank correlation coefficients $\left(r_{\mathrm{S}}\right)$ between pellets characteristics and Axis 1: total number of seeds with cereals excluded $\left(r_{\mathrm{s}}=\right.$ $0.962, P<0.0001)$; number of seeds of fleshy-fruited species $\left(r_{\mathrm{s}}=0.920, P<0.0001\right)$; number of species $\left(r_{\mathrm{s}}=0.902, P<0.0001\right)$; frequency of fragments of cereal grains $\left(r_{\mathrm{s}}=-0.670, P<0.0001\right)$; number of seeds of dry-fruited species $\left(r_{\mathrm{s}}=0.685, P<0.0001\right)$; number of cereal grains $\left(r_{\mathrm{s}}=-0.418, P<0.01\right)$ and weight of pellets $\left(r_{\mathrm{s}}=-0.359, P<0.05\right)$; Axis 2 : number number of seeds of dry-fruited species $\left(r_{\mathrm{s}}=0.533, P<0.001\right)$; number of seeds of fleshy-fruited species $\left(r_{\mathrm{s}}=-0.360, P<0.05\right)$

uneven. The frequency of pellets with seeds was low; they were present in the $18 \%$ of pellets ( $8 \%$ and $11 \%$ in the case of seeds of dry-fruited and fleshy-fruited species). There were no seeds in $87 \%$ of the analyzed pellets collected in April, in $72 \%$ of those from May and in $54 \%$ from June. The number of diaspores in one pellet in June varied between 1 and 109 and most seeds found (77\%) were present in only 5 pellets then.

All the seeds found represented 44 taxa, 7 of which were fleshy-fruited species and the pulp of their fruits was part of the rook's diet (Table 3). Dry-fruited species (34 taxa) were the most abundant. They included mainly weeds, meadow and ruderal species representing different standard dispersal modes: anemochory, myrmecochory,

Table 2 Mean values of variables characterizing seed pool in pellets. Differences analyzed with the Kruskal-Wallis test

\begin{tabular}{lccrr}
\hline Variable & April $N=384$ & May $N=275$ & June $N=80$ & $P$ \\
\hline Weight of pellet (g) & 1.44 & 1.43 & 0.87 & $<0.0001$ \\
Number of seeds/100 pellets & & & & \\
Total number (cereal grains excluded) & 10.7 & 61.4 & 452.5 & $<0.0001$ \\
Dry-fruited species & 8.3 & 13.4 & 260.0 & $<0.0001$ \\
Fleshy-fruited species & 2.3 & 47.6 & 192.5 & $<0.0001$ \\
Number of cereal grains/100 pellets & 16.4 & 3.3 & 7.5 & $<0.01$ \\
\hline
\end{tabular}


Table 3 Structure of the seed pool of pellets of the rook Corvus frugilegus. Mean number of seeds calculated per 100 pellets, frequency of the occurrence of seeds (\%) in parentheses. Dispersal mode in parentheses, classification based on external adaptations of diaspores: A - anemochory (diaspores with wings or plumes, also the smallest seeds with no dispersal adaptations); B - barochory (dispersed by gravity); Ep - epizoochory (diaspores with hooks, hairs or awns); M - myrmecochory (diaspores with elaiosomes)

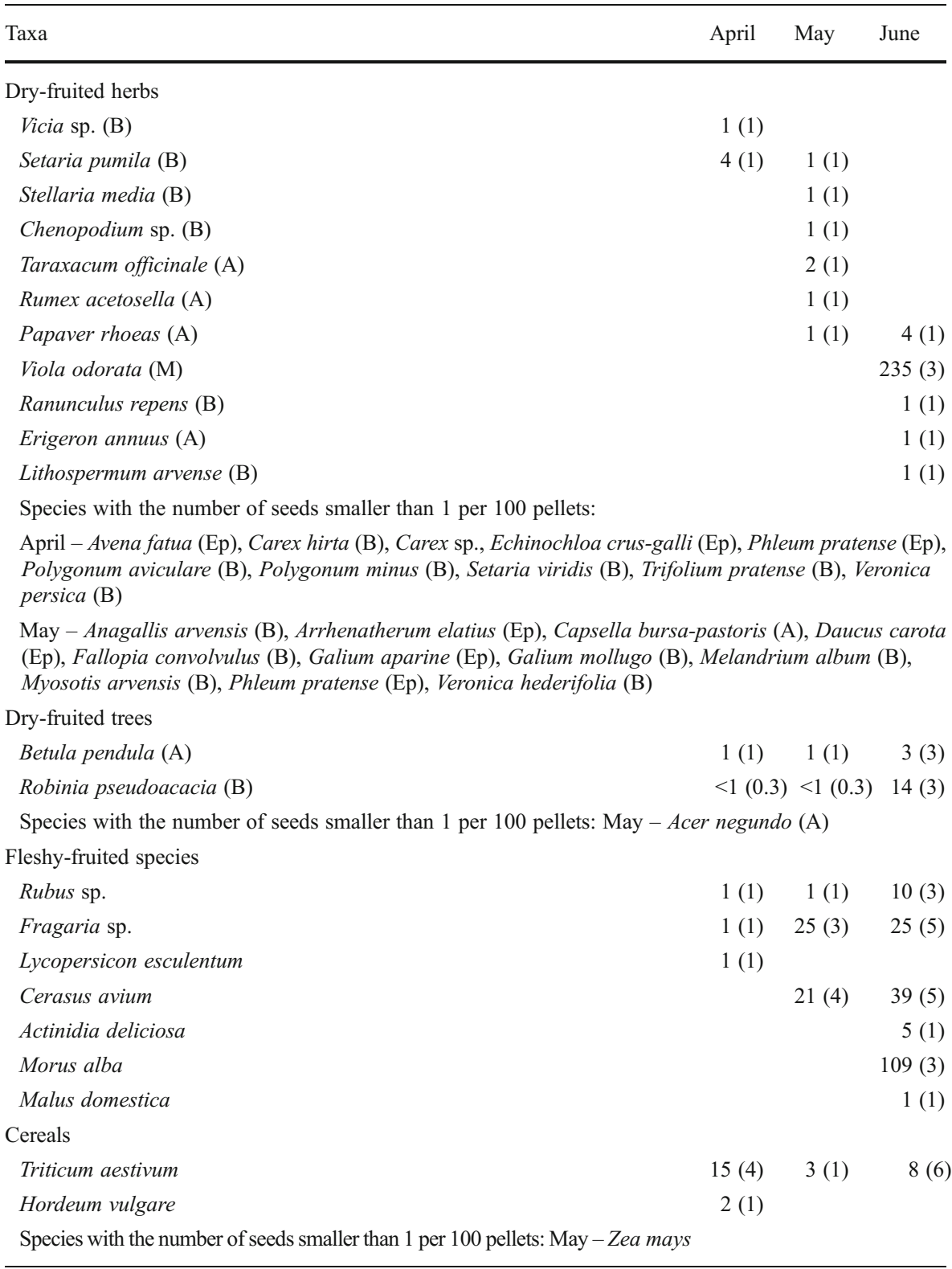

epizoochory or simply barochory (Table 3). Most species were represented by single seeds, and only in a few cases (Viola odorata, Morus alba, Cerasus avium and 
Fragaria sp.) were there more. The frequency of each single species was low; in no cases (even if the number of seeds was significant) did it exceed $5 \%$.

Our results showed high variability of the process of rook seed dispersal among years. The qualitative and quantitative structure of the transported seed pool in the two subsequent years was highly differentiated (Fig. 2, Table 4). Only in the case of site $\mathrm{C}$ was the percentage share of the main functional groups of seeds similar in both analyzed time periods (Table 4).

Seeds of 15 species germinated (Table S1 in Electronic Supplementary Material) in the greenhouse. Two aspects are worth underlining here: the informative value of this germination test is quite low because in most cases only one or a few seeds could be sown; thus it can only be said that at least in some cases seeds could be regurgitated alive and untouched. The taxa best represented in the seed pool (Viola odorata, the most abundant of dry-fruited species and Cerasus avium - a fleshyfruited one), however, did not germinate.

Most transported species were light-demanding and characteristic of open habitats, mainly arable fields (weeds), meadows and ruderal sites, and they were located in the microsites less favourable for germination and establishment. Although the total number of species recorded in the herb layer was significantly higher than in pellets, there were no significant differences between the number of weed and meadow species, and the number of ruderal ones was much higher in the herb layer (Fig. 3, Table 5). This comparison of the species structure of the seed pool of pellets and the herb layer under the breeding colonies suggested that rooks could effectively disperse seeds of weeds and meadow species that can germinate under the dense tree canopy. Field surveys proved that almost half of the species present in pellets could germinate

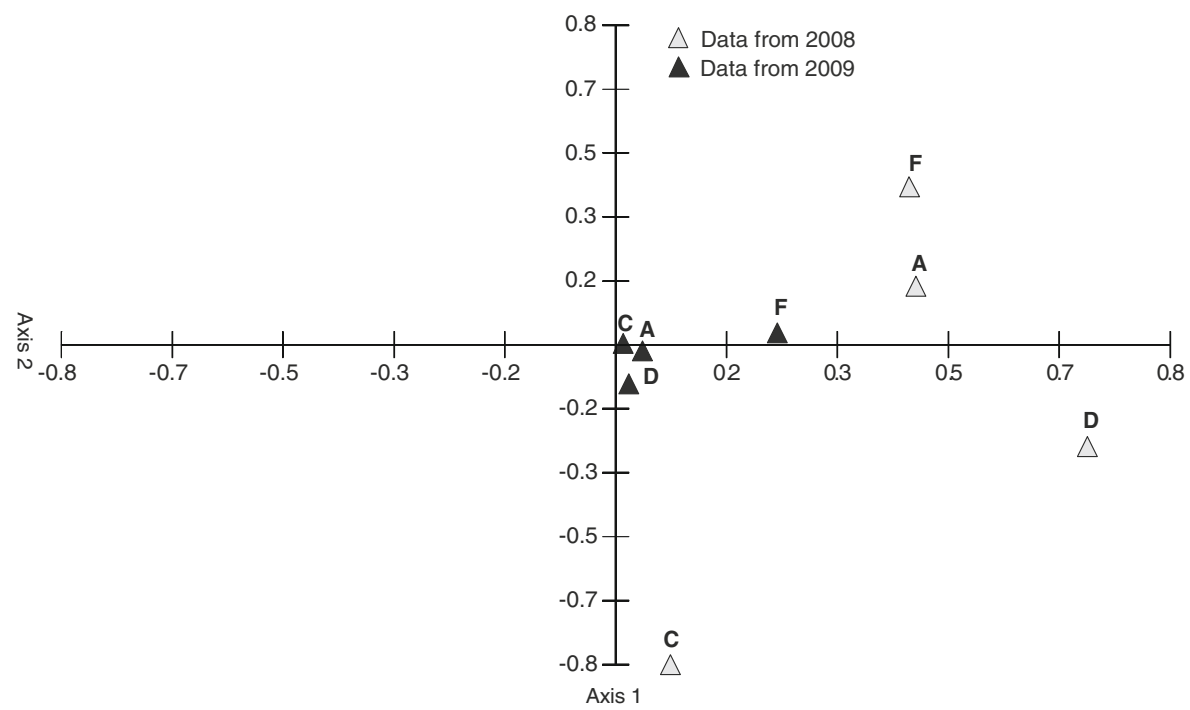

Fig. 2 Results of PCA analysis of seed pool present in pellets collected at the same sites (A, C, D, F codes) in two subsequent years. Eigenvalues: Axis 1-8500.867, Axis 2-565.260; cumulative percentage: Axis $1-89.373$, Axis $2-95.31$. Statistically significant Spearman rank correlation coefficients $\left(r_{\mathrm{S}}\right)$ between pellets characteristics and Axis 1: total number of seeds per 100 pellets $\left(r_{\mathrm{S}}=0.976, P<0.0001\right)$; number of cereal grains $\left(r_{\mathrm{s}}=0.814, P<0.05\right)$ and percentage share of seeds of dry-fruited species $\left(r_{\mathrm{s}}=-\right.$ $0.743, P<0.05)$ 
Table $4 \chi^{2}$ likelihood ratio between data from the years 2008 and 2009 (percentage share in parentheses). The structure of the seed pool in 2008 was treated as the expected value; dry-fruited herbs and trees were put in one group for the analysis; d.f. $=2$

\begin{tabular}{lccrrr}
\hline Site & Year & \multicolumn{2}{l}{ Number of seeds (\%) } & \multirow{2}{*}{$\chi^{2} ; P$} \\
\cline { 3 - 5 } & & Dry-fruited species & Fleshy-fruited species & Cereals & \\
\hline A & 2008 & $34(9)$ & $323(83)$ & $30(8)$ & $72.93 ; P<0.001$ \\
& 2009 & $29(36)$ & $45(56)$ & $6(8)$ & \\
C & 2008 & $149(67)$ & $68(31)$ & $5(2)$ & $0.63 ;$ NS \\
& 2009 & $12(63)$ & $7(37)$ & $0(0)$ & \\
D & 2008 & $7(1)$ & $570(90)$ & $58(9)$ & $234.3 ; P<0.001$ \\
& 2009 & $10(25)$ & $25(63)$ & $5(12)$ & \\
F & 2008 & $4(1)$ & $289(96)$ & $9(3)$ & $87.06 ; P<0.001$ \\
& 2009 & $15(7)$ & $184(92)$ & $2(1)$ & \\
\hline
\end{tabular}

and establish; some species (Galium aparine, Polygonum aviculare, Stellaria media and Taraxacum officinale) seemed to be quite a stable element of the herb layer of parks where the breeding colonies were established (Table S1 in Electronic Supplementary Material). Additionally, most species whose seeds were present in pellets could create a persistent seed bank (values of the longevity index LI were

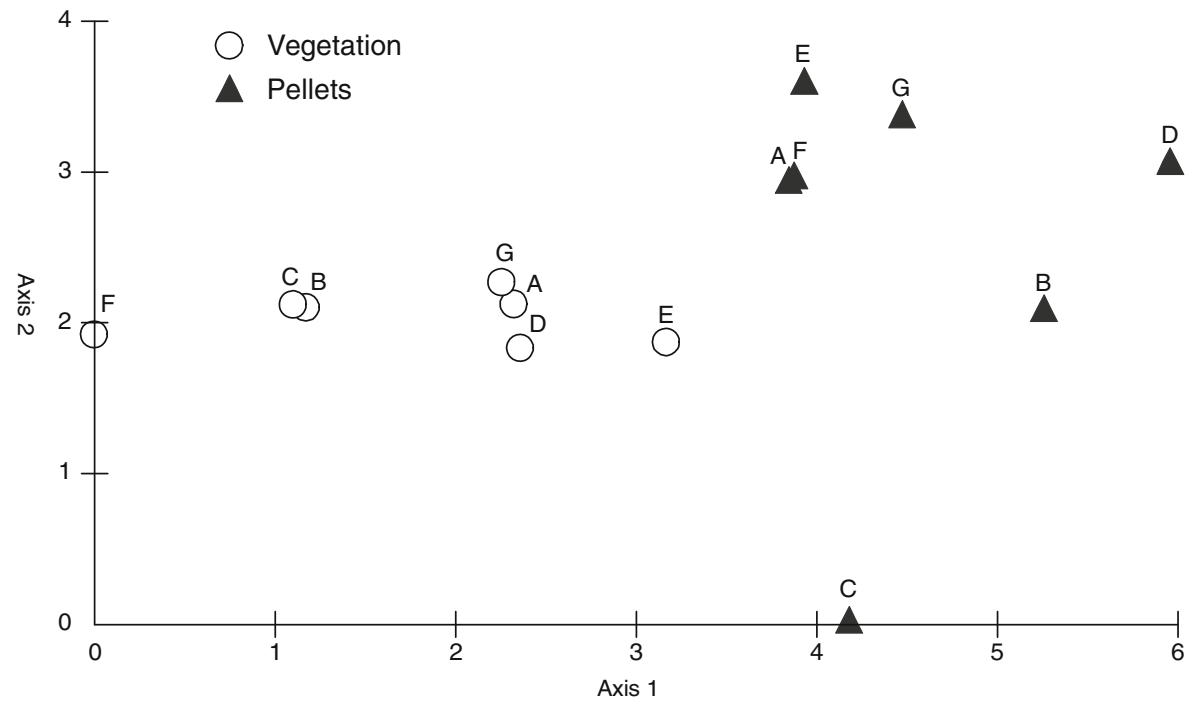

Fig. 3 Results of the DCA analysis of species composition of seed pool present in pellets and herb layer structure under colonies in 2009. Qualitative data (presence/absence of the species) were taken under consideration. Eigenvalues: Axis $1-0.725$, Axis $2-0.452$; cumulative percentage: Axis $1-15.4$, Axis $2-$ 25.0. Statistically significant Spearman rank correlation coefficients $\left(r_{\mathrm{S}}\right)$ between species data and Axis 1 : number of ruderal species $\left(r_{\mathrm{s}}=-0.775, P<0.01\right)$; number of cereal species $\left(r_{\mathrm{s}}=0.705, P<0.01\right)$ and number of woodland species $\left(r_{\mathrm{s}}=-0.556, P<0.05\right)$. Total number of species and number of weed and meadow species were not statistically significant 
Table 5 Comparison of species composition of seed pool in pellets and herb layer under breeding colonies $(N=7)$. Data of pellets' seed pool from April, May and June were put together for each colony and treated as potential seed influx. Differences were analyzed with the U Mann-Whitney test; standard deviation in parentheses

\begin{tabular}{|c|c|c|c|c|c|c|}
\hline \multirow[t]{2}{*}{ Variable } & \multicolumn{2}{|c|}{ Mean number of species } & \multirow[t]{2}{*}{$\mathrm{U} ; P$} & \multicolumn{2}{|c|}{ Percentage share } & \multirow[t]{2}{*}{$\mathrm{U} ; P$} \\
\hline & Pellets & Herb layer & & Pellets & Herb layer & \\
\hline Total & $10.6(4.9)$ & $21.1(8.5)$ & $5.5 ; P<0.05$ & - & - & - \\
\hline Cereals & $1.6(0.8)$ & $0.4(1.1)$ & $6.5 ; P<0.05$ & $15(5)$ & $1(3)$ & $1.0 ; P<0.01$ \\
\hline Weeds & $3.4(3.0)$ & $5.1(3.5)$ & $16.5 ; \mathrm{NS}$ & $30(21)$ & $23(11)$ & $20.0 ; \mathrm{NS}$ \\
\hline Meadow species & $1.4(0.8)$ & $3.1(1.9)$ & $10.5 ; \mathrm{NS}$ & $15(6)$ & $15(6)$ & $24.0 ; \mathrm{NS}$ \\
\hline Ruderal species & $0.4(0.5)$ & $9.7(3.6)$ & $0.0 ; P<0.01$ & $4(6)$ & $48(11)$ & $0.0 ; P<0.01$ \\
\hline Woodland species & $0.3(0.5)$ & $1.4(1.0)$ & $7.5 ; P<0.05$ & $2(3)$ & $6(4)$ & 9.5; NS \\
\hline
\end{tabular}

close to 1), and we can assume that they can stay alive in soil until microsite conditions become more advantageous.

\section{Discussion}

\section{Seed Predator or Seed Disperser}

In the rook's diet, animal food predominates during the breeding season. The most important plant material consumed is cereal grains (Gromadzka 1980). The number of grains and the frequency of fragments of grains in the analyzed pellets was highest in April (16.4 grains per 100 pellets; $95 \%$ of pellets contained damaged cereal grains), whereas in May it was 3.3 grains per 100 pellets and $66 \%$ of pellets contained damaged cereal grains and in June 7.5 and $39 \%$. Easily attainable fleshy fruits of Cerasus avium, Fragaria sp., Morus alba and Rubus sp. replaced the cereal grains in May and June. Analysis of gizzard content indicated invertebrates as the main food source between April and June (Gromadzka 1980). The main plant items then were cereal grains (frequency of occurrence between $96 \%$ in April and $79 \%$ in June); other items like weed seeds and underground plant parts were also present but their frequency was low. It is known that the results of diet analysis obtained with different methods vary strongly, and that the main source of a potential bias in methods can result from a different digestibility of food items (studies of the diet of the red-backed shrike Lanius collurio, Tryjanowski et al. 2003), but in our case the results coincided with the results other authors have obtained.

Weed seeds are an important food source for many bird species in agroecosystems (Wilson et al. 1999). Seeds are such a valuable food source because of their high energy content and the relatively high protein and nitrogen level in comparison to other plant material (Crawley 1997). The caloric value of weed seeds and grains is considerably high, which in practice means that shorter time is needed to sustain energy demands of birds feeding on seeds than on other plant items, which was studied in detail in the case of the grey partridge Perdix perdix (Potts 1970). We can only 
speculate about the reasons of the presence of intact seeds of dry-fruited species in the pellets of the rook collected under the breeding colonies. Small seeds of dry-fruited species (see Table S1 in Electronic Supplementary Material for details) can act as an additional food source for the bird but comparison of the number and mass of cereal grains and dry-fruited species clearly shows that the latter can only be an additional and insignificant source of food. It is known that birds that consume many seeds can also act as seed dispersers. The probability of seed dispersal by granivorous birds may be related to the large number of small seeds consumed, which is the function of seed density in the environment (Bruun and Poschlod 2006). This was observed in the case of the grey partridge consuming mainly seeds of Amaranthus retroflexus. Some swallowed seeds $(0.3 \%)$ passed through the gut of the bird undamaged and could germinate (Orłowski and Czarnecka 2009). It is also worth highlighting that much smaller granivores like the reed bunting Emberiza schoeniclus digested all the consumed seeds (Orłowski and Czarnecka 2007). Also in the case of birds occupying other habitats, e.g., shorebird species with many long-distance migrants among them, many species have been recorded as consuming and dispersing seeds. Saltmarsh seeds (mainly Chenopodiaceae) were found in 13-44\% of droppings and pellets of shorebird species wintering in Spain; seeds of 31 species (Poaceae and Chenopodiaceae among them) were present in droppings of plains-waders Pedionomus torquatus and diaspores of 122 genera were found in the stomach of the common snipe Gallinago gallinago (Green et al. 2002 and literature cited there). In droppings of the emu Dromaius novaehollandiae, an omnivorous, but mostly herbivorous bird, seeds of 77 plant species were found, $61 \%$ of which were not adapted to endozoochory (CalviñoCancela et al. 2006). Dry fruits of sedges and grasses and seeds without obvious adaptations to endozoochory were also found in droppings of Darwin's finches Geospizinae (Guerrero and Tye 2009), and in pellets and faeces of waders (Sánches et al. 2006).

Presence of dry-fruited species can also be a result of unintentional swallowing during the foraging for other food items like cereal grains or animal food, and in this case it would be an example of secondary dispersal of seeds. The probability that small seeds or dry fruits occasionally escape the digestion is higher than in the case of bigger seeds, and the role of these infrequent dispersal events mediated by seed predators may be very important for the life cycle of plants that would not normally be considered bird-dispersed (Guerrero and Tye 2009). Analyses of the diet of the reed bunting and the grey partridge based on the presence of the remains of consumed food in droppings showed the presence of large amounts of crushed seed coats in faeces when weed seeds constituted the main food source (Orłowski and Czarnecka 2007, 2009). Analyzed pellet content from the rook also contained undigested remains of plant items, mainly cereal grain fragments. No seed coats or damaged seeds of any other dry-fruited species were found. This proves that the rook is rather a disperser than a seed predator of all small-seeded dry-fruited species other than cereals, although the number of dispersed seeds is low.

\section{Post-Dispersal Fate of Seeds}

According to Shupp (1993), the effectiveness of a disperser depends on the number of seeds dispersed (quantity) and the probability that the dispersed seed will produce a 
new reproductive adult (quality). The quantity of seeds dispersed by one particular rook is small and the probability of one dispersal event is quite low. One single bird could transfer from 4 seeds per month in April up to 160 seeds in June, but the dispersal efficiency is also the function of the density of disperser population (Herrera and Jordano 1981). We tried to evaluate the number of potentially transported seeds by all birds from the studied breeding colonies - and we assumed that it could be almost 550,000 seeds during the three-month breeding period (seeds of dry-fruited species constituted half of them).

The components of the quality of dispersal are the quality of seed treatment and deposition (Shupp 1993). Seed germination depends on where the seeds were placed and the behaviour of the disperser determines the pattern of deposition (CalviñoCancela 2004). Endozoochorous plant species can be classified as specialists and generalists. Specialists selectively attract birds; seeds are transported by a few dispersers but they are usually placed in high-quality sites (safe germination sites). Generalists, in turn, attract many bird species that deposit their seeds in a large variety of habitat types (so-called "risk-spreading dispersal"; Ishaki et al. 1991). The rook, an omnivorous species, can be treated as a generalist disperser. It disperses seeds of species mostly connected with open habitats (arable fields, meadows and ruderal sites) and deposits them under the canopy of trees in rural parks. These sites cannot be assessed as safe germination sites but at least some of the species whose seeds were found in pellets could germinate there (Galium aparine, Polygonum aviculare, Taraxacum officinale and Stellaria media were observed in the herb layer in more than $50 \%$ of studies sites, Table S1 in Electronic Supplementary Material). The rook is an important disperser of walnut seeds that it would hide in ploughed fields and in field margins. A significant number of seedlings was also found there especially when the field was abandoned later (Lenda et al. 2012). The only achievable data on the quality of seed deposition by other corvids concern the common raven and seeds of fleshy-fruited species: most of these seeds were regurgitated in microsites assessed as potentially suitable (Nogales et al. 1999). Seeds were also found in pellets of migratory waders but there are currently no data on the movement of diaspores transported by waders between suitable habitats (Sánches et al. 2006).

The spatial pattern of deposition is usually clumped, which is influenced by the pattern of distribution of perching or roosting sites and the deposition of seeds in clumps after defecation or pellet regurgitation (Debussche and Isenmann 1994; Jordano et al. 2007). The number of seeds in one dropping or pellet can be high, which is not an advantageous aspect of endozoochorous dispersal. The maximum number of seeds of one species in one rook pellet was 108 (Viola odorata); in the case of pellets formed by the common raven the observed number was much higher - even 980 seeds of Ficus carica were present in one particular pellet (Nogales et al. 1999). When the number of seeds per group increases, their germination success decreases. Clumped deposition increases the probability of suffering higher predation rate and influences seedling survival by the increase of inter- or intraspecific competition (Barnea et al. 1992; Pizo and Simão 2001; Paulsen and Högstedt 2002). But in the case of multi-seeded fleshy fruits the rook ingestion reduced the number of seeds in one group. The maximum number of Fragaria sp. seeds per pellet was only 19; usually we found only a few seeds of this species in one particular regurgitation pellet. The process of reducing the density of seeds of fleshy-fruited species by birds 
in pellets was also observed by Clergean (1992) and Barnea et al. (1992). Big seeds of Hedera helix and Prunus sp. were regurgitated alone one after another, small seeds regurgitated in groups were mixed with other indigested material (Clergean 1992). Additionally, seeds of the palm Enterpe edulis were much less clumped in regurgitation pellets than in bird faeces (Pizo and Simão 2001).

Viable seeds that did not germinate at the place of their deposition can enter the soil seed bank. In the case of rabbit endozoochory, $33 \%$ of seeds entering the seed bank were dispersed within faeces (Pakeman et al. 1999). Small-seeded species are more likely to be dispersed by endozoochory (Janzen 1984), because the small size and round shape enable them to survive ingestion; these external features are also characteristic of the species creating the persistent soil seed bank (Pakeman et al 1999, 2002). Most dry-fruited species found in the rook's regurgitation pellets were small-seeded and they created a persistent soil seed bank (Table S1 in Electronic Supplementary Material).

Chambers (1999) distinguished "vectors in spread", which are the rook in our study, and "agencies of establishment", affecting or altering local substrate and light conditions to make them suitable for germination and growth. For most species present in rook pellets, local disturbances could promote their germination. Tree fall and herb layer removal were responsible for promoting germination and establishment at two study sites in our preliminary studies of seed dispersal by the rook (Czarnecka and Kitowski 2010). A considerable number of weed and ruderal seeds was found in the soil seed bank of forest community (Turkey oak-sessile oak forest) adjacent to abandoned vineyard that served as a source of weed propagules. Their germination was hampered by high canopy cover but an increase of weed and ruderal herb cover was foreseen if canopy opened (Koncz et al. 2011). Searching for "agencies of establishment" seems to be another interesting aspect of the studies of dispersal mediated by the rook and other corvids connected with agricultural landscape of Central Europe.

\section{Conclusion}

Our study showed that the rook, an omnivorous bird species, can act as an important seed dispersal agent, especially for species of agricultural landscape without any obvious adaptation to endozoochory. Dry-fruited species found in the rook's regurgitation pellets are mostly characteristic of open habitats: arable lands, ruderal sites and meadows. The most important factor responsible for the structure of the seed pool transported by the rook is the time when pellets were regurgitated. This means that the type and availability of food determines the number and species structure of dispersed seeds. Seeds are placed in microsites under the dense canopy, which is a disadvantageous aspect of the dispersal mediated by the rook, but some species found in pellets can germinate under the dense tree canopy (weeds, meadow and ruderal species) and most create persistent seed banks, thus increasing the possibility of potential seed germination and seedling establishment when environmental conditions change.

Acknowledgements We thank three anonymous reviewers for discussion, comments and valuable remarks on this paper. 
Open Access This article is distributed under the terms of the Creative Commons Attribution License which permits any use, distribution, and reproduction in any medium, provided the original author(s) and the source are credited.

\section{References}

Barnea A, Yom-Tov Y, Friedman J (1992) Effect of frugivorous birds on seed dispersal and germination of multi-seeded fruits. Acta Oecol 13:209-219

Benvenuti S (2007) Weed seed movement and dispersal strategies in the agricultural environment. Weed Biol Managem 7:141-157

Biaduń W (2005) Synurbic population of Corvidae in Lublin. In Jerzak L, Kavanagh BP, Tryjanowski P (eds) Ptaki krukowate Polski (Corvids of Poland). Bogucki Wydawnictwo Naukowe, Poznań, pp 461-472

Bruun HH, Poschlod P (2006) Why are small seeds dispersed through animal guts: large numbers or seed size per se? Oikos 113:402-411

Calviño-Cancela M (2004) Ingestion and dispersal: direct and indirect effects of frugivores an seed viability and germination of Corema album (Empetraceae). Acta Oecol 26:55-64

Calviño-Cancela M, Dunn RR, van Etten EJB, Lamont BB (2006) Emus as non-standard seed dispersers and their potential for long-distance dispersal. Ecography 29:632-640

Chambers FM (1999) Comment on D. M. Wilkinson (1997). 'Plant colonization are wind dispersed seeds really dispersed by birds at larger spatial and temporal scales?' J Biogeogr 26:425-427

Clergean P (1992) The effect of birds on seed germination of fleshy-fruited plants in temperate farmland. Acta Oecol 13:679-686

Crawley MJ (1997) Plant-herbivore dynamics. In Crawley MJ (ed) Plant ecology. Blackwell Science, Oxford, pp 401-474

Czarnecka J, Kitowski I (2010) Seed dispersal by the rook Corvus frugilegus L. in agricultural landscape mechanisms and ecological importance. Polish J Ecol 58:511-523

Debussche M, Isenmann P (1994) Bird dispersed seed rain and seedling establishment in patchy Mediterranean vegetation. Oikos 69:414-426

Eriksson O, Ehrlén J (1992) Seed and microsite limitation of recruitment in plant population. Oecologia 91:360-364

Fahring L, Merriam G (1992) Conservation of fragmented populations. Conservation Biol 8:50-59

Garcia D, Zamora R, Amico GC (2010) Birds as suppliers of seed dispersal in temperate ecosystems: conservation guidelines from real-world landscape. Conservation Biol 24:1070-1079

Green A, Figuerola J, Sánchez MI (2002) Implications of waterbird ecologu for dispersal of aquatic organisms. Acta Oecol 23:177-189

Gromadzka J (1980) Food consumption and food consumption of the rook Corvus frugilegus in agrocoenoses in Poland. Acta Ornithol 17:227-255

Guerrero AM, Tye A (2009) Darwin's Finches as seed predators and dispersers. Wilson J Ornithol 121:752-764

Herrera CM, Jordano P (1981) Prunus mahaleb and birds: the high efficiency seed dispersal system of a temperate fruiting tree. Ecol Monographs 51:203-218

Higgins SI, Nathan R, Cain ML (2003) Are long distance dispersal events in plants usually caused by non-standard means of dispersal? Ecology 84:1945-1956

Howe HF, Smallwood J (1982) Ecology of seed dispersal. Ann Rev Ecol Syst 13:201-228

Ishaki I, Walton PB, Safriel UN (1991) Seed shadow generated by frugivorous birds in eastern mediterranean scrub. J Ecol 79:575-590

Jabłoński B (1979) Food of the rook, Corvus frugilegus L. in different parts of its territory. Przeglad Zool 23:67-80

Jadczyk P, Jakubiec Z (2005) Wintering of rooks Corvus frugilegus in Poland. In Jerzak L, Kavanagh BP, Tryjanowski P (eds) Ptaki krukowate Polski (Corvids of Poland). Bogucki Wydawnictwo Naukowe, Poznań, pp 541-556

Jakubiec Z (2005a) Rook Corvus frugilegus in Poland - current knowledge and research perspectives. In Jerzak L, Kavanagh BP, Tryjanowski P (eds) Ptaki krukowate Polski (Corvids of Poland). Bogucki Wydawnictwo Naukowe, Poznań, pp 89-111

Jakubiec Z (2005b) Habitat use and daily activity of foraging Rooks Corvus frugilegus in the agricultural landscape in Wielkopolska (W Poland). In Jerzak L, Kavanagh BP, Tryjanowski P (eds) Ptaki krukowate Polski (Corvids of Poland). Bogucki Wydawnictwo Naukowe, Poznań, pp 333-354 
Janzen D (1984) Dispersal of small seeds by big herbivores: foliage is the fruit. Amer Naturalist 123:338-353 Jordano P, Forget PM, Lambert JE, Böhning-Gaese K, Traveset A, Wright SJ (2011) Frugivores and seed dispersal: mechanisms and consequences for biodiversity of a key ecological interaction. Biol Lett 7:321-323

Jordano P, Garcia C, Godoy JA, Garcia-Castño JL (2007) Differential contribution of frugivores to complex seed dispersal patterns. Proc Natl Acad Sci USA 104:3278-3282

Kasprzykowski Z (2003) Habitat preferences of foraging rooks Corvus frugilegus during the breeding period in agricultural landscape of eastern Poland. Acta Ornithol 38:27-31

Koncz G, Török P, Papp M, Matus G, Tóthmérész B (2011) Penetration of weeds into the herbaceous understorey and soil seed bank of Turkey oak-sessile oak forest in Hungary. Commun Ecol 12:227-233

Kovach WL (2005) MVSP - A MultiVariate Statistical Package for Windows, ver. 3.1. Kovach Computing Services, Pentraeth, Wales

Lenda M, Skórka P (2009) Orzech włoski Juglans regia - nowy, potencjalnie inwazyjny gatunek w rodzimej florze (Walnut Juglans regia - a new, potentially invasive species in native flora). Chrońmy Przyr Ojczysta 65:261-270

Lenda M, Skórka P, Knops JMH, Moron D, Tworek S, Woyciechowski M (2012) Plant establishment and invasions: an increase in a seed disperser combined with land abandonment causes an invasion of the non-native walnut in Europe. Proc Roy Soc London B 279:1491-1497

Levey DJ, Silva WR, Galetti M (2002) Seed dispersal and frugivory: ecology, evolution and conservation. CABI Publishing, Wallingford

Luniak M (1977) Consumption and digestion of food by the Rook, Corvus frugilegus L. in the condition of an aviary. Acta Ornithol 16:213-240

Mirek Z, Piękoś-Mirkowa H, Zając A, Zając M (2002) Flowering plants and pteridophytes of Poland. A checklist. W Szafer Institute of Botany, Polish Academy of Sciences, Kraków

Myers JA, Vellend M, Gardescu S, Marks PL (2004) Seed dispersal by white-tailed deer: implications for long-distance dispersal, invasion, and migration of plants in eastern North America. Oecologia 139:35-44

Nogales M, Delgado JD, Medina FM (1998) Shrikes, lizards and Lycium intricatum (Solanaceae) fruits: a case of indirect seed dispersal on an oceanic island (Alegranza, Canary Islands). J Ecol 86:866-871

Nogales M, Hernández EC, Valdés F (1999) Seed dispersal by common ravens Corvus corax among island habitats (Canarian Archipelago). Ecoscience 6:56-61

Nogales M, Padilla DP, Nieves C, Illera JC, Traveset A (2007) Secondary seed dispersal system, frugivorous lizards and predatory birds in insular volcanic badlands. $J$ Ecol 95:1394-1403

Orłowski G, Czapulak A (2007) Different extinction risks of the breeding colonies of Rook Corvus frugilegus in rural and urban areas of SW Poland. Acta Ornithol 42:145-155

Orłowski G, Czarnecka J (2007) Winter diet of reed bunting Emberiza schoeniclus in fallow and stubble fields. Agric Ecosyst Environm 118:244-248

Orłowski G, Czarnecka J (2009) Granivory of birds and seed dispersal: viable seeds of Amaranthus retroflexus L. recovered from the droppings of the grey patridge Perdix perdix L. Polish J Ecol 57:191-196

Orłowski G, Kasprzykowski Z, Zawada Z, Kopij G (2009) Stomach content and grit ingestion by Rook Corvus frugilegus nestings. Ornis Fenn 86:117-122

Ozinga WA, Bekker RM, Schaminée JH, van Groenendael JM (2004) Dispersal potential in plant communities depends on environmental conditions. J Ecol 92:767-777

Ozinga WA, Schaminée JHJ, Bekker RM, Bonn S, Poschold P, Tackenberg O, Bakker J, van Groenendael JM (2005) Predictability of plant species composition from environmental conditions is constrained by dispersal limitation. Oikos 108:555-561

Pakeman RJ, Digneffe G, Small JL (2002) Ecological correlates of endozoochory by herbivores. Funct Ecol 16: 296-304

Pakeman RJ, Engelen J, Attwood JP (1999) Rabbit endozoochory and seed bank buid-up in acidic grasslands. Pl Ecol 145:83-90

Państwowy Monitoring Środowiska (2007) Monitoring flagowych gatunków ptaków. Instrukcja dla obserwatorów (Monitoring of Flagships Species of Birds. Instructions for Birdwatchers). Available at: www.monitoringptakow.gios.gov.pl (in Polish)

Patterson IJ, Dunnet GM, Fordham RA (1971) Ecological studies of the Rook, Corvus frugilegus L., in north-east Scotland. Dispersion. J Appl Ecol 8:815-833

Paulsen TR, Högstedt G (2002) Passage through bird guts increases germination rate and seedling growth in Sorbus aucuparia. Funct Ecol 16:608-616

Pizo MA, Simão J (2001) Seed deposition pattern and the survival of seeds and seedlings on the palm Enterpe edulis. Acta Oecol 22:229-233 
Poschold P, Bonn S (1998) Changing dispersal processes in the central European landscape since the last ice age: an explanation for the actual decrease of plant species richness in different habitats. Acta Bot Neerl 47:27-44

Potts GR (1970) Studies on the changing role of weeds of the genus Polygonum in the diet of the partridge Perdix perdix L. J Appl Ecol 7:567-576

Ptaszyk J, Winiecki A (2005) Rooks Corvus frugilegus in the Wielkopolska region: breeding population size, its changes and some elements of breeding biology. In Jerzak L, Kavanagh BP, Tryjanowski P (eds) Ptaki krukowate Polski (Corvids of Poland). Bogucki Wydawnictwo Naukowe, Poznań, pp 557576

Reebs SG, Boag DA (1987) Regurgitated pellets and late winter diet of Black-Billed magpies Pica pica in Central Alberta. Canad Field Nat 101:108-110

Sánches MI, Green AJ, Castellanos EM (2006) Internal transport of seeds by migratory waders in the Odiel marshes, south-west Spain: consequences for long-distance dispersal. J Avian Biol 37:201-206

Sekercioglu CH (2006) Increasing awareness of avian ecological function. Trends Ecol Evol 21:464-471

Shupp EW (1993) Quantity, quality and the effectiveness of seed dispersal by animals. Vegetatio 107/ 108:15-29.

Spiegel O, Nathan R (2007) Incorporating dispersal distance into the disperser effectiveness framework: frugivorous birds provide complementary dispersal to plants in a patchy environment. Ecol Lett 10:718-728

Thompson K, Bakker JP, Bekker RM (1997) The soil seed banks of north west Europe: methodology, density and longevity. Cambridge University Press, Cambridge

Thompson K, Bakker JP, Bekker RM, Hodgson JG (1998) Ecological correlates of seed persistence in soil in the NW European flora. $J$ Ecol 86:163-169

Trakhtenbrot A, Nathan R, Perry G, Richardson DM (2005) The importance of long-distance dispersal in biodiversity conservation. Diversity Distrib 11:173-181

Tryjanowski P, Karg MK, Karg J (2003) Food of the Red-backed Dhrike Lanius collurio: a comparision of three methods of diet analysis. Acta Ornithol 38:59-64

Tryjanowski P, Kuźniak S, Kujawa K, Jerzak L. (2009) Ekologia ptaków krajobrazu rolniczego (Ecology of birds of agriculture landscape). Bogucki Wydawnictwo Naukowe, Poznań

Vander Wall SB, Longland W (2004) Diplochory: are two seed dispersers better than one? Trends Ecol Evol 19:155-161

Wang BC, Smith TB (2002) Closing the seed dispersal loop. Trends Ecol Evol 17:379-385

Wilkinson DM (1997) Plant colonization: are wind dispersed seeds really dispersed by birds at larger spatial and temporal scale? J Biogeogr 24:61-65

Wilson JD, Morris AJ, Arroyo BE, Clark SC, Bradbury RB (1999) A review of the abundance and diversity of invertebrate and plant foods of granivorous birds in northern Europe in relation to agricultural change. Agric Ecosyst Environm 75:13-30

Received: 24 January 2011 /Revised: 14 February 2012 / Accepted: 21 February 2012 /

Published online: 29 August 2012 